\title{
Monogenoidea on exotic Indian freshwater fishes. 2. Range expansion of Thaparocleidus caecus and $T$. siamensis (Dactylogyridae) by introduction of striped catfish Pangasianodon hypophthalmus (Pangasiidae)
}

\author{
A. TRIPATHI ${ }^{1}$, S. RAJVANSHI ${ }^{2}$, N. AGRAWAL ${ }^{2}$ \\ ${ }^{1}$ Department of Zoology, Rajiv Gandhi University, Itanagar- 791 112, Arunachal Pradesh, India, \\ E-mail: tripathi_amit02@yahoo.co.in; ${ }^{2}$ Department of Zoology, Lucknow University, Lucknow- 226007, \\ Uttar Pradesh, India;
}

\begin{abstract}
Summary
Thaparocleidus caecus and Thaparocleidus siamensis are parasitic monogeneans found on the gills of striped catfish Pangasianodon hypophthalmus (Pangasiidae), a native species of Southeast Asia. We report $T$. caecus and $T$. siamensis, for the first time in India, from the gills of aquarium-kept $P$. hypophthalmus (prevalence $40 \%$ and $80 \%$ respectively). We also report $T$. siamensis from the gills of pond-cultured $P$. hypophthalmus (prevalence $100 \%$ ); no specimen of $T$. caecus was observed on pondcultured $P$. hypophthalmus (prevalence $0 \%$ ). Morphometric data of the studied parasites did not differ significantly from previous descriptions of the two species recovered in other geographic locations. Similarly, no consequential variation was found when $28 \mathrm{~S}$ rDNA of $T$. siamensis from the present study was compared with that of $T$. siamensis from Malaysia available on GenBank. The present investigation adds to growing cases of freshwater monogeneans that have been concomitantly introduced worldwide as a result of aquarium and aquaculture trade.
\end{abstract}

Keywords: Range expansion; Monogenoidea; Thaparocleidus siamensis; Thaparocleidus caecus; Pangasianodon hypophthalmus; India

\section{Introduction}

The Striped catfish Pangasianodon hypophthalmus Sauvage, 1878 (Pangasiidae), a native of Mekong, Chao Phraya, and Maeklong basins of Southeast Asia (Roberts \& Vidhayanon, 1991), is an excellent candidate for aquaculture and aquarium trade. The fish has been introduced as a source of aquaculture into river basins of many Asian countries (Roberts \& Vidthayanon, 1991; Rainboth, 1996; Froese \& Pauly, 2012), including India (Singh \& Lakra, 2012). In addition, it is exported to 136 countries across all continents (Silva \& Phuong, 2011), and its juveniles are available as ornamental fish for the aquarium trade in many countries (Baska et al., 2009). In fact, the farming of $P$. hypophthalmus has achieved such phenomenal growth over the last three decades that it has become a 'global icon of aquaculture development' (Silva \& Phuong, 2011) with its production and distribution levels matching that of tilapia, carps and salmon. Despite this increasing socioeconomic importance of $P$. hypophthalmus culture, the parasitic fauna associated with this enterprise is not well studied (Thuy et al., 2010; Silva \& Phuong, 2011).

\section{Material and methods}

As part of our continuing effort on cataloguing the monogenean parasites (Platyhelminthes) from exotic Indian freshwater fishes (see Tripathi et al., 2010), we found specimens of Thaparocleidus caecus (Mizelle \& Kritsky, 1969) Lim, 1996, and Thaparocleidus siamensis (Lim, 1990) Lim, 1996 from the gills of $P$. hypophthalmus purchased from the aquarium market of Lucknow $\left(26^{\circ} 50^{\prime} \mathrm{N} / 80^{\circ} 56^{\prime} \mathrm{E}\right) \quad(21.08 .2012)$. Additionally, we found $T$. siamensis from the gills of $P$. hypophthalmus collected from the fish farms at Barabanki $\left(26^{\circ} 55^{\prime} \mathrm{N} / 81^{\circ} 11^{\prime} \mathrm{E}\right)(24.07 .2011)$. The prevalence and intensity of infestation of the worms isolated in the present study were recorded (Table 1 and 2). Some parasite specimens were mounted in glycerine and Canada balsam for studying their hard and soft body parts respectively, using the protocol recommended by Kritsky et al. (1986); others were preserved in absolute ethanol for DNA extraction. The mounted parasites were photographed with a digital camera (Olympus photometrics coolsnap) attached to a phase-contrast microscope (Olympus BX51). Based on these photographs, measurements were obtained with the software ProExpress 6.0 (Media Cybernetics, Inc., USA). Voucher specimens have been deposited in the Natural History Museum, London (2013.8.12.1-10, 2013.8.12.1120). 
Table 1. Prevalence and intensity of $T$. caecus and $T$. siamensis infestation on aquarium-kept $P$. hypophthalmus

\begin{tabular}{lcc}
\hline & T.caecus & T. siamensis \\
\hline Prevalence & $40 \%(4 / 10)$ & $80 \%(8 / 10)$ \\
Intensity & $30+$ & $200+$ \\
\hline
\end{tabular}

DNA was extracted from the individual specimen of $T$. siamensis (query species) using the Qiagen's Dneasy blood and tissue Kit (Qiagen, Germany). The extracted DNA $(10 \mu \mathrm{l})$ was used as a template in a PCR reaction to amplify the partial 28S rDNA, using forward (5'ACCCGCTGAATTTAAGCAT-3') and reverse (5'CTCTTCAGAGTACTTTTCAAC-3') primers. The reaction volume was $25 \mu \mathrm{l}$, containing $2 \mu \mathrm{l}$ polymerase chain reaction (PCR) buffer $(10 \mathrm{X}), 0.5 \mu \mathrm{l}$ dNTPs $(10 \mathrm{mM})$, $0.5 \mu \mathrm{l}$ forward primer (19.6 nMol.), $0.5 \mu 1$ reverse primer (31.9 nMol.), $0.5 \mu \mathrm{l}$ Taq polymerase (5 Units), $1 \mu \mathrm{l}$ $\mathrm{MgCl} 2(25 \mathrm{mM}), 5 \mu \mathrm{l}$ genomic DNA and $15 \mu \mathrm{l}$ miliQ water. PCR conditions were $95{ }^{\circ} \mathrm{C}$ for 4 min (initial denaturation), followed by 35 cycles of $95^{\circ} \mathrm{C}$ for $1 \mathrm{~min}$ (denaturation), $55^{\circ} \mathrm{C}$ for $45 \mathrm{sec}$ (annealing), $72^{\circ} \mathrm{C}$ for $1 \mathrm{~min}$ (extension) and $72{ }^{\circ} \mathrm{C}$ for $10 \mathrm{~min}$ (final extension). An aliquote $(10 \mu \mathrm{l})$ from the amplicon was electrophoresed in a $1.5 \%$ agarose gels in TAE buffer, stained with ethidium bromide, and visualized under UV illuminator. The remaining amplicons were sequenced with the same primers using 3730/ABI-3730XL-1409-023 automated sequencer (Xcelris Labs Limited, India).

Sequencing products were subjected to BLAST (Basic Local Alignment Search Tool) for homology search. Aligned sequences of $28 \mathrm{~S}$ rDNA of $T$. siamensis from the present study and that of Malaysia (available on GenBank under accession number AF218123.1) were compared using the SDSC (San Diego Supercomputer Center) work bench, and multiple sequence alignments were made by ClustalW (Thompson et al. 1994). Texshade (colour coded
Table 2. Prevalence and intensity of T. caecus and T. siamensis infestation on pond-cultured $P$. hypophthalmus

\begin{tabular}{lcc}
\hline & T. caecus & T. siamensis \\
\hline Prevalence & $0 \%(0 / 4)$ & $100 \%(4 / 4)$ \\
Intensity & 0 & $250+$ \\
\hline
\end{tabular}

plots) of aligned sequences was used for conserved, nonconserved and identical sequences. Sequences were deposited in GeneBank under the accession number JX947852.

\section{Results and discussion}

\section{Taxonomy}

Thaparocleidus caecus was originally described as Ancylodiscoides caecus Mizelle and Kritsky, 1969 from an unidentified aquarium fish collected in United States (Mizelle \& Kritsky, 1969). Gussev (1978), however, transferred the species to Silurodiscoides Gussev, 1976 as Silurodiscoides caecus (Mizelle \& Kritsky 1969) n. comb. Lim (1990) redescribed $S$. caecus based on new material and also described the new species, S. siamensis, both from Pangasianodon hypophthalmus pond cultured in Malaysia. Subsequently, Lim (1996) considered Silurodiscoides Gussev, 1976, a junior subjective synonym of Thaparocleidus Jain, 1952, based on the law of priority. Accordingly, the scientific names of $S$. caecus and S. siamensis were changed to T. caecus (Mizelle \& Kritsky, 1969) Lim, 1996 and T. siamensis (Lim, 1990) Lim, 1996 respectively. We compared our specimens of $T$. caecus and $T$. siamensis from India with the respective redesrciption and description by Lim (1990), which we considered detailed and the most adequate representation of the two species. The general morphology and measurements of male and female reproductive organs, and haptoral parts of our specimens (Figs. 1 and 2) are consistent with the details provided by Lim (1990), and the diagnostic features of Thaparocleidus
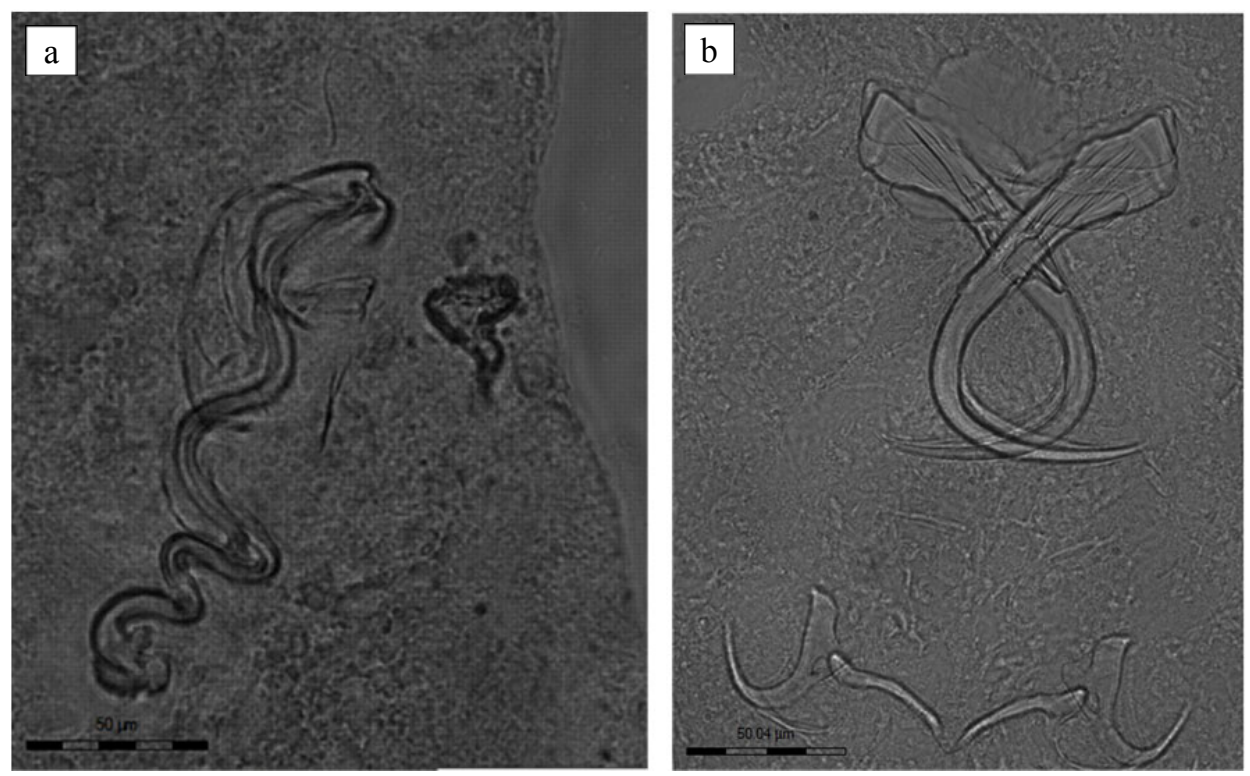

Fig. 1. Copulatory complex and vagina (a) and haptoral sclerites (b) of Thaparocleidus siamensis (Lim, 1990) Lim, 1996. Scale bar $=50 \mu \mathrm{m}$. 

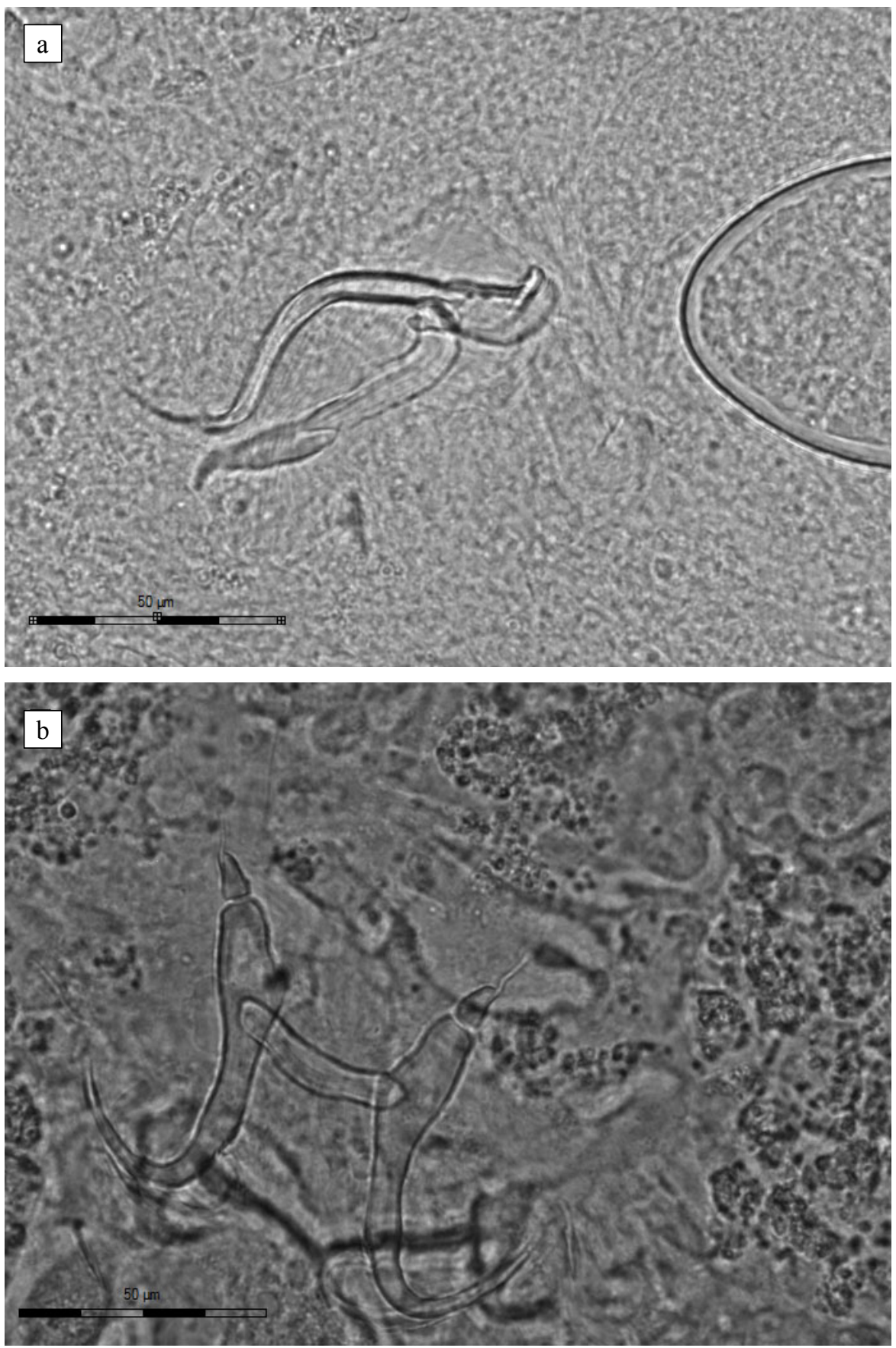

Fig. 2. Copulatory complex (a) and haptoral sclerites (b) of Thaparocleidus caecus (Mizelle \& Kritsky, 1969) Lim, 1996. Scale bar $=50 \mu \mathrm{m}$.

(Lim et al., 2001). Additionally, we have shown the morphology of the vagina to be inverted cone shaped in $T$. siamensis which Lim (1990) missed (Fig. 1). The morphometric data for T. caecus and T. siamensis examined are presented in Table 3 and Table 4 and compared with data reported by other authors. Molecular analysis also demonstrated that the specimens of $T$. siamensis from India, and those in Malaysia differ by only five bases (Figs. 3 and 4). In other words, the specimens of T. siamensis from India and those in Malaysia have $99.3 \%$ similarity (MVIEW Multiple Alignment Display) and are thus similar species.

\section{Range expansion}

Mizelle and Kritsky (1969) described T. caecus from an unidentified aquarium fish imported into the United States from Thailand. Subsequently, Lim (1990) redescribed $T$. caecus from $P$. hypophthalmus (imported from Thailand and cultured) in Malaysia. Lim (1990) also described $T$. siamensis on the same host. Lerssutthichawal et al. (1999) recorded T. caecus from three host fishes: Pangasius conchophilus, Pangasius larnaudii and P. hypophthalmus, and $T$. siamensis from $P$. hypophthalmus cultured in Thailand. Pariselle et al. (2002) recorded T. caecus from both $P$. hypophthalmus and Pangasius djambal and T. siamensis 
Table 3. Morphometric data (presented in $\mu \mathrm{m}$ as means followed by ranges in parentheses) of Thaparocleidus caecus from Pangasianodon hypophthalmus in India (present study), Malaysia (Lim 1990), and USA (Mizelle \& Kritsky 1969)

\begin{tabular}{|c|c|c|c|}
\hline Parameters measured & Present study & $\operatorname{Lim}(1990)$ & $\begin{array}{c}\text { Mizelle \& Kritsky } \\
(1969)\end{array}$ \\
\hline \multicolumn{4}{|l|}{ Body } \\
\hline Total body length & $1038(680-1230)$ & $833(333-1000)$ & $904(768-1055)$ \\
\hline Total body width & $167(120-200)$ & $149(124-183)$ & $176(140-251)$ \\
\hline Pharynx diameter & $48(36-60)$ & - & $81(68-95)^{*}$ \\
\hline Haptor length & $125(80-150)$ & - & $115(96-137)$ \\
\hline Haptor width & $110(77-150)$ & - & $144(111-179)$ \\
\hline \multicolumn{4}{|l|}{ Male reproductive organs } \\
\hline Testis length & $113(36-150)$ & - & - \\
\hline Testis width & $63(30-80)$ & - & - \\
\hline Copulatory tube length & $60(48-70)$ & $62(60-64)$ & $66(61-71)$ \\
\hline Accessory piece length & $43(34-53)$ & $41(40-44)$ & $49(40-54)$ \\
\hline \multicolumn{4}{|l|}{ Female reproductive organs } \\
\hline Ovary length & $141(60-120)$ & - & - \\
\hline Ovary width & $67(40-100)$ & - & - \\
\hline \multicolumn{4}{|l|}{ Haptoral parts } \\
\hline Dorsal anchor length & $39(37-41)$ & $43(40-44)$ & $46(45-48)$ \\
\hline Dorsal anchor recurved point length & $11(10-13)$ & $12(12-14)$ & - \\
\hline Dorsal anchor patch length & $6(4-7)$ & $8(7-9)$ & - \\
\hline Ventral anchor length & $17(16-19)$ & $20(19-21)$ & $21(20-22)$ \\
\hline Ventral anchor recurved point length & $6(5-7)$ & $8(8-10)$ & - \\
\hline Dorsal bar length & $42(29-44)$ & $44(44-52)$ & $32(29-34)$ \\
\hline Ventral bar length & $25(21-27)$ & $25(22-26)$ & $50(44-59)$ \\
\hline Hooks length & $14(14-15)$ & $11(10-12)$ & $12(11-19)$ \\
\hline \multicolumn{4}{|l|}{ Egg } \\
\hline Egg length (with filament) & $77(56-91)$ & - & - \\
\hline Egg width & $41(33-50)$ & - & - \\
\hline
\end{tabular}

*Width of pharynx

from P. hypophthalmus (imported from Thailand and cultured) in Indonesia. They also described $T$. vietnamensis on $P$. hypophthalmus and Pangasius bocourti. Das et al. (2006) recorded $T$. siamensis from $P$. hypophthalmus (imported from Thailand and cultured) in Bangladesh. Thuy \& Buchmann (2008) recorded both T. siamensis and T. caecus from $P$. hypophthalmus cultured in Vietnam. Wiecaszek et al. (2009) recorded T. caecus from an aquarium escapee pangasiid (either $P$. hypophthalmus or the hybrid of $P$. hypophthalmus with some unknown ornamental fish, presumably imported from Thailand) in Poland. Baska et al. (2009) recorded 'Thaparocleidus monogeneans' from $P$. hypophthalmus fry (imported from Thailand to pet fish shops) in Hungary and Russia; although parasites could not be identified to species level, given the high level of monogenean host specificity, and their coevolution with their host, they were possibly either
T. siamensis or T. caecus or even both.

In India, Rastogi et al. (2008) were apparently the first to record a monogenean parasite from aquarium-kept Puntius sutchii (now Pangasianodon hypophthalmus). However, these authors completely misidentified the parasite species for the formerly described Silurodiscoides vistulensis (Siwak 1932) Gusev 1973 (now Thaparoclidus vistulensis (Siwak 1932) Lim 1996). The copulatory organ, as illustrated by Rastogi et al. (2008), in particular, is not even close to that of $T$. vistulensis. Indeed, the monogenean illustrated by Rastogi et al. (2008) corresponds more to $T$. siamensis than $T$. vistulensis, to which this article is a testimony. Singh \& Lakra (2012) also noted 'gill fluke infection' in all $P$. hypophthalmus farms in India, but neither the generic nor the specific identity of these parasites was established. Thus, ours is the first published account of $T$. siamensis and T. caecus from India, which also represents 


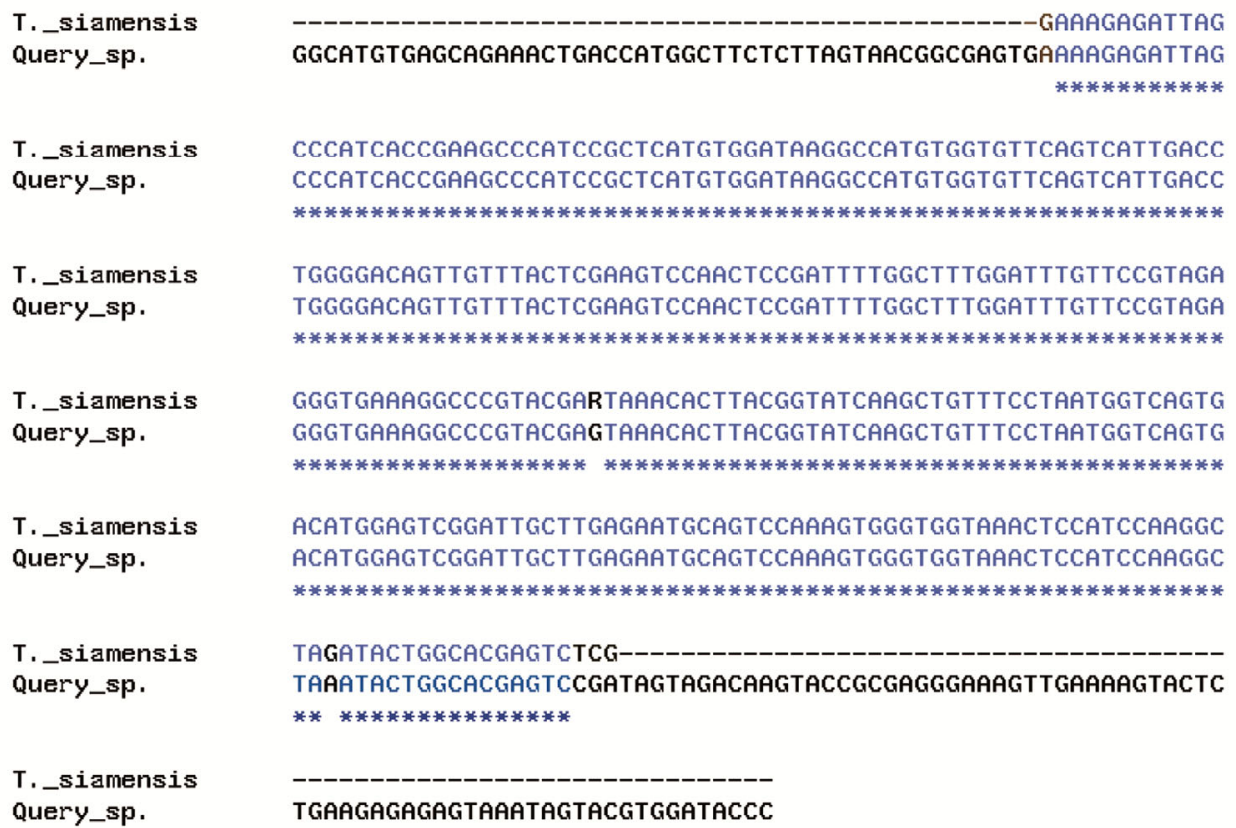

Fig. 3. ClustalW alignment a range extension of these two species to South Asia. The extent of global distribution of these two parasite species also exemplifies the potential of exotic fish to concomitantly introduce their monogeneans into areas outside of their natural range (see Tripathi, 2013 for discussion).

Disease risk implications

The pathological implications of these monogeneans are not well studied. Nonetheless, the sporadic mortality of $P$.

Table 4. Morphometric data (presented in $\mu \mathrm{m}$ as means followed by ranges in parentheses) of Thaparocleidus siamensis from Pangasianodon hypophthalmus in India (present study) and Malaysia (Lim 1990)

\begin{tabular}{lcc}
\hline Parameters measured & Present study & Lim (1990) \\
\hline Body & & - \\
Total body length & $822(695-1139)$ & - \\
Total body width & $140(90-170)$ & - \\
Pharynx diameter & $40(30-50)$ & - \\
Haptor length & $118(90-175))$ & - \\
$\quad$ Haptor width & $93(70-145)$ & - \\
Male reproductive organs & & - \\
Testis length & $131(90-180)$ & - \\
Testis width & $64(45-95)$ & - \\
Copulatory tube length & $96(90-97)$ & $97(90-100)$ \\
Accessory piece length & $129(121-138)$ & $120(110-134)$ \\
Female reproductive organs & & \\
Ovary length & $124(90-188)$ & \\
Ovary width & $65(50-85)$ & - \\
Vagina length & $37(20-50)$ & \\
Haptoral parts & & - \\
Dorsal anchor length & $60(58-64)$ & $64(60-70)$ \\
Dorsal anchor recurved point length & $30(27-35)$ & $33(28-38)$ \\
Dorsal anchor patch length & $30(24-35)$ & $30(24-36)$ \\
Ventral anchor length & $19(15-21)$ & $23(22-24)$ \\
Ventral anchor recurved point length & $12(9-15)$ & $13(12-14)$ \\
Dorsal bar length & $38(31-40)$ & $40(36-44)$ \\
Ventral bar length & $28(25-32)$ & $28(24-30)$ \\
Hooks length & $12(12-13)$ & $14(13-15)$ \\
& & \\
Egg length (with filament) & $237(147-385)$ & - \\
Egg width & $25(19-30)$ & - \\
\hline
\end{tabular}




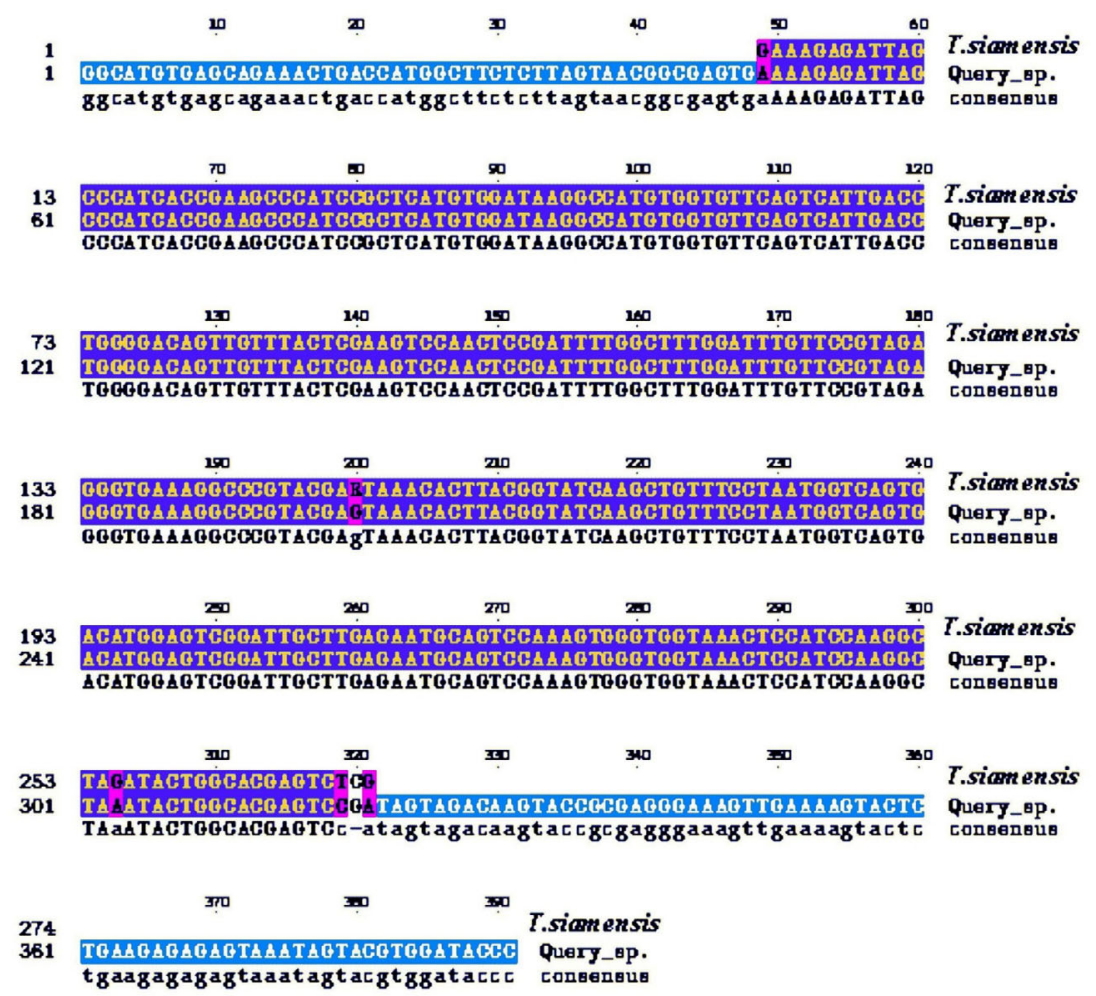

Fig. 4. Texshade showing colour coded plots for conserved sequence (light blue colour), all match sequence (blue colour) and similar sequence (purple colour) and non-match sequence (white colour)

hypophthalmus due to T. siamensis and T. caecus infestation has been documented in Vietnam (Thuy \& Buchmann, 2008). In India, Singh and Lakra (2012), who were not aware of taxonomic status of monogeneans from $P$. hypophthalmus, also reported, "gill fluke infection common in all $P$. hypophthalmus farms with infection rate varying from $60-90 \%$ and highest mortality during the first week after stocking". Indeed, the intensities of infestation by $T$. siamensis in the present study reached higher than 200 parasites per aquarium-kept fish and 250 parasites per pond-cultured fish, which makes it difficult to envisage that such a high parasitic burden would not exert a strongly adverse effect on the host survival. Further studies are required to estimate their pathogenicity accurately.

An additional disease risk involved, especially in Indian conditions where the culture sites of $P$. hypophthalmus are very close to open water (Singh \& Lakra, 2012), is the spread and colonisation of $P$. hypophthalmus and associated monogeneans to sympatric wild fish. The fish was previously known to have established a small population of it in the lake Kinneret, Israel as an aquarium escapee (Snovsky \& Golani, 2012) and is thus capable of establishing elsewhere, including India. Should the escapee $P$. hypophthalmus establish its population in Indian waters, it can trickle across state boundaries and disseminate its monogeneans to further new localities for a combination of two reasons: 1) $P$. hypophthalmus is highly potamodromous and can cover distances of over several hundred kilometres (FAO 2013), and 2) India has one of the largest networks of rivers in the world (Rao, 1975).

Wiecaszek et al. (2009) contended that T. caecus, because of its very narrow host-specificity, poses no threat to the native ichthyofauna of Europe. However, a thorough examination of the literature reveals that $T$. caecus can actually exploit a range of pangasiid hosts (Table 3 ). Evidently, $T$. caecus is a generalist parasite with wide host specificity, and thus most likely to represent a natural threat to native fish biodiversity of importing countries.

Table 5. Fish species reported as hosts of Thaparocleidus caecus

\begin{tabular}{ll}
\hline Host fish & Reference \\
\hline Pangasiidae & \\
Pangasianodon hypophthalmus & Lim (1990); Lerssutthichawal et al. (1999); Pariselle et al. (2002); Thuy \& \\
& Buchmann (2008); Wiecaszek et al. (2009); Baska et al. (2009); Present \\
& study \\
Pangasius conchophilus & Lerssutthichawal et al. (1999) \\
Pangasius larnaudii & Lerssutthichawal et al. (1999) \\
Pangasius djambal & Pariselle et al. (2002) \\
\hline
\end{tabular}


Considering continuing worldwide introductions/exports of $P$. hypophthalmus for aquarium and/or aquaculture purposes, we anticipate further range expansion for these parasites. It seems only relevant and essential that parasitologists consider the potential impact of parasites onto the economically important $P$. hypophthalmus farming.

\section{Acknowledgements}

To Monisha Banerjee (Lucknow University, India) for helping with the molecular analysis; and University Grant Commission, India [39-603/2010 (SR)] and Department of Science and Technology, India [SR/SO/AS-56/2011] for providing financial assistance to Amit Tripathi.

\section{References}

Baska, F., Voronin, V. N., Eszterbauer, E., Muller, L., Marton, S., Molnar, K. (2009): Occurrence of two myxosporean species, Myxobolus hakyi sp. n. and Hoferellus pulvinatus sp. n., in Pangasianodon hypophthalmus fry imported from Thailand to Europe as ornamental fish. Parasitol. Res., 105 (5): 1391 - 1398. DOI: 10.1007/s00436-009-1567-x.

Das, A. K., Chandra, K. J., Ghosh, P. K., Biswas, S. R. (2006): Parasitic monogenea of three exotic fish species to Bangladesh waters. Indian J. Anim. Sci., 76 (2): 168 - 173

FAO. 2010 - 2013. Cultured aquatic species information programme. Pangasius hypophthalmus. Cultured aquatic species information programme. Text by GRIFFITHS, D., VAN Khanh, P., Trong, T. Q. In: FAO Fisheries and Aquaculture Department (online). Rome. Updated 14 January 2012, retrieved April 9, 2013

Froese R., Pauly D. (2007): Fish base. Retrieved November 2, 2012 from www.fishbase.org

GuseV, A. V. (1978): Monogenoidea of freshwater fishes. Principles of systematics, analysis of world fauna and its evolution. Parasitol. Sbor., 38: 96 - 198. [In Russian.]

Kritsky, D. C., Thatcher, V. E., Boeger, W. A. (1986): Neotropical Monogenea. 8. Revision of Urocleidoides (Dactylogyridae, Ancyrocephalinae). Proc. Helminthol. Soc. Wash., 53 (1): $1-37$

Lerssutthichawal, T., Lim, S. L. H., Chinabut S. (1999): Monogeneans from the pangasiid fishes of Thailand. AAHRI Newsletter, 8 (1): 1 - 5

LIM, S. L. H. (1990): Silurodiscoides Gussev, 1961 (Monogenea: Ancyrocephalidae) from Pangasius sutchi Fowler, 1931 (Pangasiidae) cultured in Peninsular Malaysia. Raffles Bull. Zool., 38 (1): 55 - 63

LIM, S. L. H. (1996): Thaparocleidus Jain, 1952, the senior synonym of Silurodiscoides Gussev, 1976 (Monogenea: Ancylodiscoidinae). Syst. Parasitol., 35 (3): 207 - 215. DOI: $10.1007 / \mathrm{BF} 00009640$

LiM, L. H. S., Timofeeva, T. A., GiBSON, D. I. (2001): Dactylogyridean monogeneans of the siluriform fishes of the Old World. Syst. Parasitol., 50(3), 159 - 197. DOI: 10.1023/A:1012237801974

Mizelle, J. D., KRITSKY D. C. (1969): Studies on Mono- genetic Trematodes. XXXIX. Exotic species of Monopisthocotylea with the proposal of Archidiplectanum gen. n. and Longihaptor gen. n. Am. Midl. Nat., 81: $370-386$

PARISElle, A., LIM, L. H. S., LAMBERT, A. (2002): Monogeneans from Pangasiidae (Siluriformes in Southeast Asia: III. Five new species of Thaparocleidus Jain, 1952 (Ancylodiscoididae) from Pangasius bocourti, P. djambal and P. hypophthalmus. Parasite, 9: $207-217$

RAO, K. L. (1975): India's water wealth: its assessment, uses and projections. New Delhi, India, Orient Longman, $255 \mathrm{pp}$.

RaInBoth, W. J. (1996): Fishes of the Cambodian Mekong. Food and Agriculture Organization of the U.N. Rome, $265 \mathrm{pp}$.

Rastogi, P., Mishra, D., Rastogi, R., Sharma, V., SingH, H. S. (2008): On a New Species of Genus Silurodiscoides (Achmerow, 1964) Gussev, 1973 with redescription, copulation biology and Neuroanatomy of S. vistulensis (New Combination) from Meerut (UP), India. Asian J. Exp. Biol. Sci., 22 (3): 329 - 342

Roberts, T. R., VidThayanon, C. (1991): Systematics revision of the Asian Catfish family Pangasiidae, with biological observation and description of three new species. Proc. Acad. Nat. Sci. Philadelphia, 143: $97-144$

Silva, S. S. D., PhuOng, N. T. (2011): Striped catfish farming in the Mekong Delta, Vietnam: a tumultuous path to a global success. Rev. Aquac., 3 (2): 45 - 73. DOI: 10.1111/j.1753-5131.2011.01046.x

SingH, A. K., LAKRA, W. S. (2012): Culture of Pangasianodon hypophthalmus into India: Impacts and present scenario. Pak. J. Biol. Sci., 15 (1): 19 - 26. DOI: 10.3923/pjbs.2012.19.26

SNOVSKY, G., Golani, D. (2012): The occurrence of an aquarium escapee, Pangasius hypophthalmus (Sauvage, 1878), (Osteichthys, Siluriformes, Pangasiidae) in Lake Kinneret (Sea of Galilee), Israel. Bioinvasions Rec., 1 (2): 101 - 103. DOI: 10.3391/bir.2012.1.2.03

Thompson, J. D., Higgins, D. G., Gibson, T. J. (1994): ClustalW: improving the sensitivity of progressive multiple sequence alignment through sequence weighting, position-specific gap penalties and weight matrix choice. $\mathrm{Nu}$ cleic Acids Res., 22 (22): 4673 - 4680. DOI: $10.1093 /$ nar/22.22.4673

THUY, D. T., BUCHMANN, K. (2008): Infections with gill parasitic monogeneans Thaparocleidus siamensis and $T$. caecus in cultured Catfish Pangasius hypophthalmus in Southern Vietnam. Bull. Eur. Assoc. Fish Pathol., 28 (1): $10-15$

Thuy, D.T., Kania, P., Buchmann, K. (2010): Infection status of zoonotic trematode metacercariae in Sutchi catfish (Pangasianodon hypophthalmus) in Vietnam: Associations with season, management and host age. Aquaculture, $302 \quad$ (1): $19 \quad-\quad 25 . \quad$ DOI: 10.1016/j.aquaculture.2010.02.002

Tripathi, A., Agrawal, N., SRivastava, N. (2010): Monogenoidea on exotic Indian freshwater fishes. 1. A new geographical record of Sciadicleithrum iphthimum Kritsky, Thatcher, and Boeger, 1989 (Dactylogyridae) with 
the first description of its egg. Comp. Parasitol., 77 (1): 83 - 86. DOI: $10.1654 / 4382.1$

TRIPATHI, A. (2013): The invasive potential of parasitic monogenoids (platyhelminthes) via the aquarium fish trade: an appraisal with special reference to India. Reviews in Aquaculture 5: 1 - 15. DOI: 10.1111/raq.12035

RECEIVED JULY 12, 2013
Więcaszek, B., KeszKa, S., Sobecka, E., Boeger, W. A. (2009): Asian pangasiids- an emerging problem for European inland waters? systematic and parasitological aspects. Acta Ichthyologica Et Piscatoria, 39 (2): 131 - 138. DOI: 10.3750/AIP2009.39.2.08

ACCEPTED JANUARY 7, 2014 